\title{
Properties of Styrene-Butadiene Rubber Nanocomposites Reinforced with Carbon Black, Carbon Nanotube, Graphene, Graphite
}

\author{
Sung-Ho Song ${ }^{\dagger}$, O-Seok Kwon, Ho-Kyun Jeong, Yong-Gu Kang \\ NEXEN Tire corporation R\&D Center, 30, Yusan-Dong, Yangsan-Si, Kyungnam, Korea 626-230
}

(Received December 1, 2009 : Received in revised form February 9, 2010 : Accepted February 10, 2010)

\begin{abstract}
The characteristics of all polymer composites containing carbon materials are determined by four factors: component properties, composition, structure and interfacial interactions. The most important filler characteristics are particle size, size distribution, specific surface area and particle shape. As a consequence, in this paper we discuss the aspects of the mechanical, electrical and thermal properties of composites with different fillers of carbon black, carbon nanotube (CNT), graphene and graphite and focus on the relationship between factors and properties, as mentioned above. Accordingly, we fabricate rubber composites that contain various carbon materials in carbon black-based and silica based-SBR matrixes with dual phase fillers and use scanning electron microscopy, Raman spectroscopy, a rhometer, an Instron tensile machine, and a thermal conductivity analyzer to evaluate composites' mechanical, fatigue, thermal, and electronic properties. In mechanical properties, hardness and 300\%-modulus of graphene-composite are sharply increased in all cases due to the larger specific surface. Also, it has been found that the thermal conductivity of the CNT-composite is higher than that of any of the other composites and that the composite with graphene has the best electrical properties.
\end{abstract}

Key words carbon black, carbon nanotube, graphene, graphite, styrene butadiene rubber (SBR).

\section{Introduction}

The high and reversible deformability of elastomers is of great industrial importance. However, the initial modulus and durability of such material is low, and an additional reinforcing material is required for practical use. Carbon black and silica particles have been used extensively for this purpose. ${ }^{1-3)}$ And in order to create new material systems with superior properties, various nanoparticles have been also used as reinforcing fillers in elastomeric matrices. These nanometerscale reinforcing particles include spherical particles such as silica or titania, ${ }^{4-6)}$ platelets such as layered silicate $^{7-9)}$ or clay fibers ${ }^{10)}$ and multiwall or single-wall carbon nanotubes. ${ }^{11-12)}$ Especially, nano-sized carbon material particles within a host matrix have proved to be an excellent approach for exhibiting greatly improved mechanical properties.

Carbon exists in many modifications: three dimensional crystals (diamond, graphite), two-dimensional graphene, onedimensional nanotubes and zero-dimensional fullerenes. Graphite is layered crystal with c-axis lattice and carbon atoms within a layer are convalently bonded. Graphite is

Corresponding author

E-Mail : sh.song@nexentire.co.kr (S. H. Song) well known for its high strength and high thermal conductivity, it offers the possibility of making multifunctional composites in a cost effective way. Carbon nanotube (CNT) is molecule-scale tubes of graphitic carbon with outstanding properties and exhibits exceptional mechanical, thermal and electrical properties. And Graphene is defined as a flat monolayer of carbon atoms tightly packed into a two-dimensional honeycomb lattice. Along with its unique structure, graphene possesses a range of unusual properties: most notably the thermal conductivity and mechanical stiffness may rival the original values of graphite; the strength may be comparable to that of carbon nanotubes; and individual graphene is found to have excellent electronic properties.

Nanocomposites of polymers with previous carbon nanomaterials have been shown to exhibit a significant increment in the properties of polymers and even generate certain new properties that cannot be derived from their counterparts, as the mixing of phases in them occurs over a much smaller length scale in comparison to micronmeter length scale of conventional composites. ${ }^{13)}$ Therefore, in recent years, nanoparticles based composites have drawn considerable attentions. The most promising materials are polymer/ CNT nanocomposites, ${ }^{14-17)}$ polymer/graphene nanocomposites, ${ }^{18-22)}$ polymer/graphite nanoplatelet nanocomposites. ${ }^{23-25)}$ 
The objective of the present study is to fabricate composite materials that contain carbon nanofillers $(\mathrm{C} / \mathrm{B}$, CNT, Graphene, Graphite) in Carbon Black-based and Silica based-SBR matrix with the dual phase fillers respectively and to evaluate their mechanical, thermal and electrical properties.

\section{Experimental Procedure}

\subsection{Materials}

The matrix material was a Styrene Butadiene Rubber (SBR) from Kumho petrochem Co. Ltd., Korea. The SBR 1500 was consisted of $23 \%$ styrene and $77 \%$ butadiene. Carbon based nanofillers used in this study are a carbon black N339 (OCI Co. Ltd.), a Carbon Nanotube (MWNT, Carbon Nanotech Co. Ltd.), a graphene (N-Baro Tech Co. Ltd.), a graphite (Timcal Co. Ltd.). And N-tert-butyl-benzothiazole sulfonamide (TBBS) N-Cyclohexylbenzo thiazole (CBS) and N,N'-Diphenylguanidine (DPG) with a role of curatives were purchased from Shandong Shanxian Co. Ltd., China. Zinc oxide ( $\mathrm{ZnO})$, stearic acid (S/A), sulfur and Aromatic Oil (A\#2) were purchased from standard local suppliers. Also, X-50S (Daussa.co.Ltd), silane coupling agent, is silicon-based chemical that contains two types of reactivity-inorganic and organic, and acts at an interface between an silica and rubber to bond.

\subsection{Composition fabrication}

The carbon based nanofillers/SBR composites were prepared following standard procedures. First, the SBR compounds were mixed with 50phr (parts per hundred of rubber) carbon black and $70 \mathrm{phr}$ silica separately in banbury mixer at a rotor speed $60 \mathrm{rpm}$ for master batches (MB). And then, the SBR compounds with $3.5 \mathrm{phr}$ CNT, Graphene, Graphite were prepared according to the Carbon Black and Silica based fillers respectively. The additives and vulcanization agents were added at the end since it helped to start the curing process of the mixture. The compounds were placed in the aluminum mold and cured at $160^{\circ} \mathrm{C}$ for $\mathrm{T}_{90}$ by rheometer under pressure. The formulations of the reinforcing fillers/SBR composites are summarized in Table 1.

\subsection{Characterization and measurements}

Scanning electron microscopy (SEM, JEOL JSM-6490LV) was used to observe the morphology of the carbon based nanofillers. Since Carbon nanofillers are conductive, the particles could be examined at $20 \mathrm{KV}$ accelerating voltage without gold coating. Raman spectroscopy was mainly used to verify the natures of carbon materials and the overall homogeneities of the samples. The Raman Spectra, obtained in the range $1000 \sim 2000 \mathrm{~cm}^{-1}$, shows a band at $1588 \mathrm{~cm}^{-1}$ (G-band) due to the vibration mode, and a band at $1357 \mathrm{~cm}^{-1}$ (D-band) arising from the disordered-induced mode.

The electrical resistance of these manufactured composites was examined using the two-prove method in the TERAOHM, MI2077 at room temperature and the thermal conductivity was characterized by thermal conductivity analyzer (QTM-500).

Table 1. Formulation of the reinforcing fillers / SBR composites. (unit: phr)

\begin{tabular}{|c|c|c|c|c|c|c|c|c|c|c|}
\hline & $1(\operatorname{Ref} 1)$ & 2 & 3 & 4 & 5 & $6(\operatorname{Ref} 2)$ & 7 & 8 & 9 & 10 \\
\hline SBR & 100 & 100 & 100 & 100 & 100 & 100 & 100 & 100 & 100 & 100 \\
\hline $\begin{array}{c}\text { Carbon } \\
\text { Black }\end{array}$ & 50 & 53.5 & 50 & 50 & 50 & - & 3.5 & - & - & - \\
\hline Silica & - & - & - & - & - & 70 & 70 & 70 & 70 & 70 \\
\hline CNT & - & - & 3.5 & - & - & - & - & 3.5 & - & - \\
\hline Graphene & - & - & - & 3.5 & - & - & - & - & 3.5 & - \\
\hline Graphite & - & - & - & - & 3.5 & - & - & - & - & 3.5 \\
\hline $\mathrm{X}-50 \mathrm{~S}$ & - & - & - & - & - & 11.2 & 11.2 & 11.2 & 11.2 & 11.2 \\
\hline $\mathrm{ZnO}$ & 3 & 3 & 3 & 3 & 3 & 3 & 3 & 3 & 3 & 3 \\
\hline Stearic acid & 1 & 1 & 1 & 1 & 1 & 1 & 1 & 1 & 1 & 1 \\
\hline Sulfur & 1.75 & 1.75 & 1.75 & 1.75 & 1.75 & 1 & 1 & 1 & 1 & 1 \\
\hline TBBS & 1 & 1 & 1 & 1 & 1 & - & - & - & - & - \\
\hline CBS & - & - & - & - & - & 1.5 & 1.5 & 1.5 & 1.5 & 1.5 \\
\hline DPG & - & - & - & - & - & 1.5 & 1.5 & 1.5 & 1.5 & 1.5 \\
\hline $\mathrm{A \# 2}$ & 37.5 & 37.5 & 37.5 & 37.5 & 37.5 & 37.5 & 37.5 & 37.5 & 37.5 & 37.5 \\
\hline
\end{tabular}



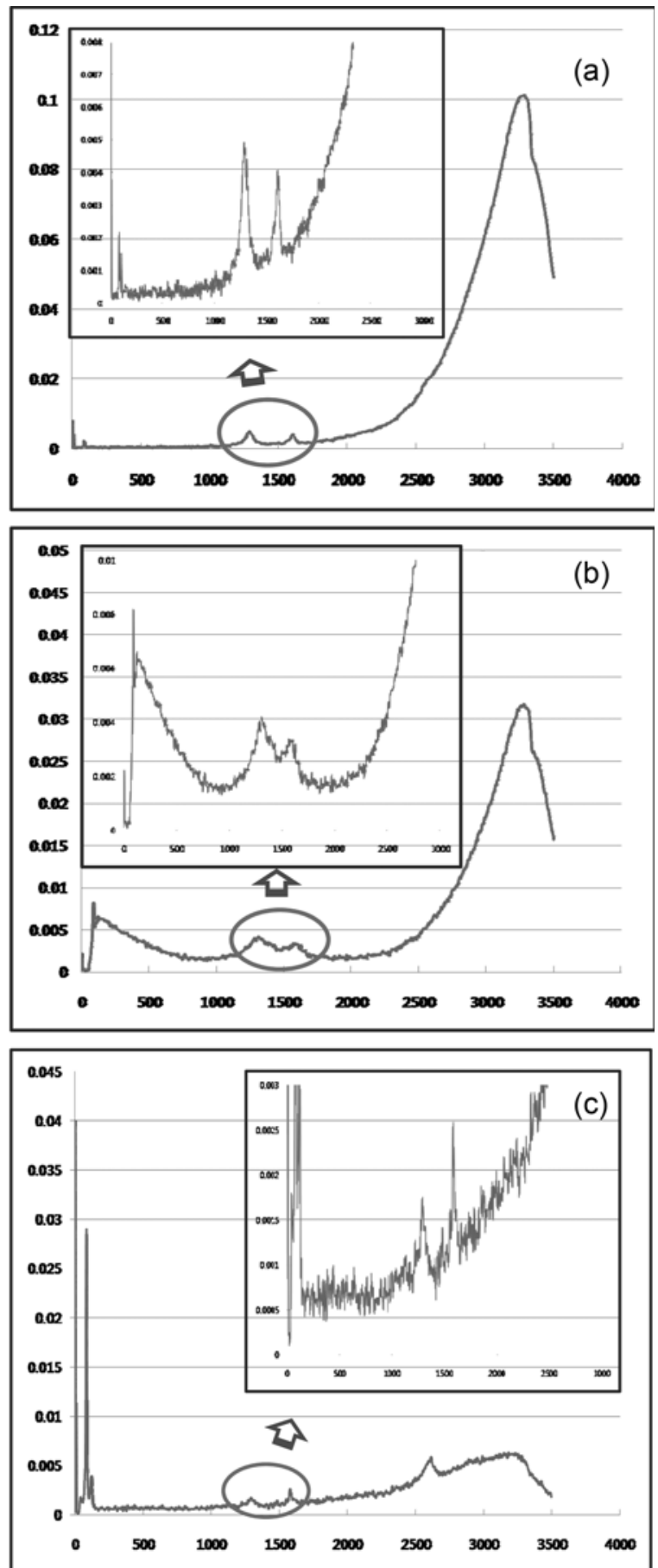

Fig. 1. Raman spectroscopy of (a) CNT (b) graphene and (c) graphite.

Curing characteristics were measured over 30-min period at $160^{\circ} \mathrm{C}$ using a moving-die rheometer (DRM-100(LP171)). Tensile tests were carried out in an Instron tensile machine (Intron Co. UK) at a crosshead speed of 300 $\mathrm{mm} / \mathrm{min}$. The dumbbell shape samples were $100 \mathrm{~mm}$ in length, $1 \mathrm{~mm}$ in thickness and $5 \mathrm{~mm}$ in width. At least four tests were carried out for each case.
Table 2. Raman spectroscopy results of CNT, graphene and graphite.

\begin{tabular}{cccc}
\hline & D band & G band & $\mathrm{I}(\mathrm{D}) / \mathrm{I}(\mathrm{G})$ \\
\hline CNT & 0.00492 & 0.00404 & $122 \%$ \\
Graphene & 0.00422 & 0.00337 & $125 \%$ \\
Graphite & 0.00337 & 0.0035 & $96 \%$ \\
\hline
\end{tabular}

Shore A hardness was measured by using a hand-held shore A durometer according to TECLOCK. The fatigue properties of composites were characterized by using Demmattia (UESHIMA).

\section{Results and Discussion}

\subsection{Materials characterization}

Fig. 1 and Table 2 show the Raman spectroscopy of carbon nanofillers. The main features in the Raman spectroscopy of carbon nanofillers are the so-called G and D bands, which lies at around 1588 and $1357 \mathrm{~cm}^{-1}$ respectively. All carbon nanofillers are observed $G$ and D bands, and $\mathrm{I}(\mathrm{D}) / \mathrm{I}(\mathrm{G})$ ratio of graphene is higher than any other materials. This result suggests minimal damage of graphite and significant devastation of graphene.

Microstructures of carbon materials were examined by SEM, and are shown in Fig. 2. Fig. 2a shows highly entangled and randomly organized CNT, and Fig. $2 b$ shows the worm-like shape of graphene. And also Fig. 2c shows irregular honeycomb network of graphite sheets and reveals the dense structures composed of many graphite sub-layers.

\subsection{Characterization of Carbon Materials/ Rubber composites}

The curing curves of carbon nanofillers/rubber composites and some parameters of curing properties are shown in Fig. 3, Fig. 4 and Table 3.

Three regions are observed in Fig. 3 and Fig. 4. The first region is the scorch delay or induction period where the torque of compounds decreased. The second region is where the curing reaction occurred. The network structure was formed in this period, leading to the sharp increment of the torque. In third region, curing curves reached to a plateau when the network matured by equilibrium. The cure time of rubber composites using Graphene is faster than other rubber composites in both Carbon Black-Based Compoistes (CBC) and Silica-Based Composites (SBC). The reason for the shorter cure time of the rubber composite using Graphene is probably due to the more spacious 


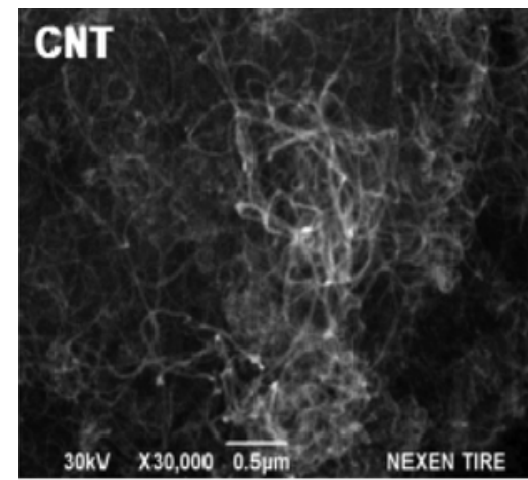

a)

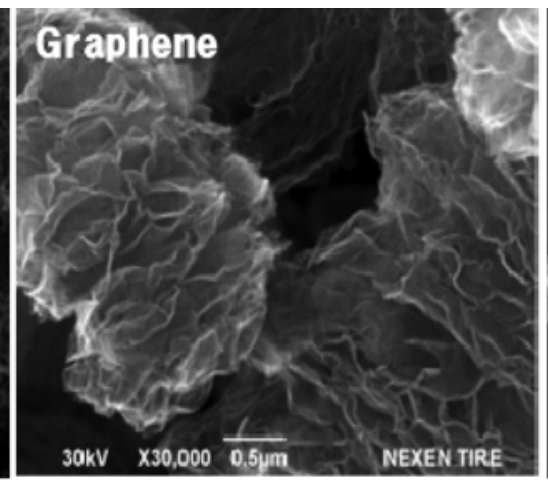

b)

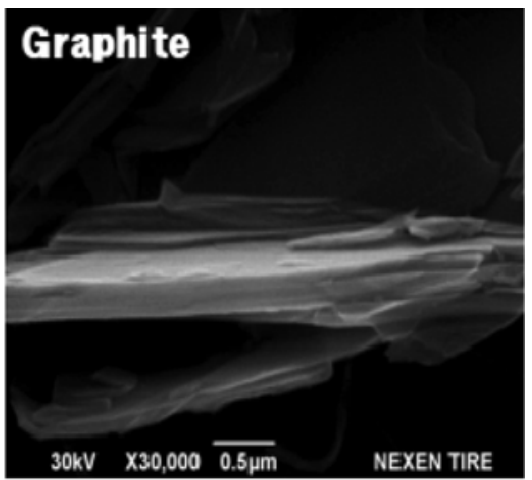

c)

Fig. 2. SEM image of (a) CNT (b) graphene and (c) graphite.

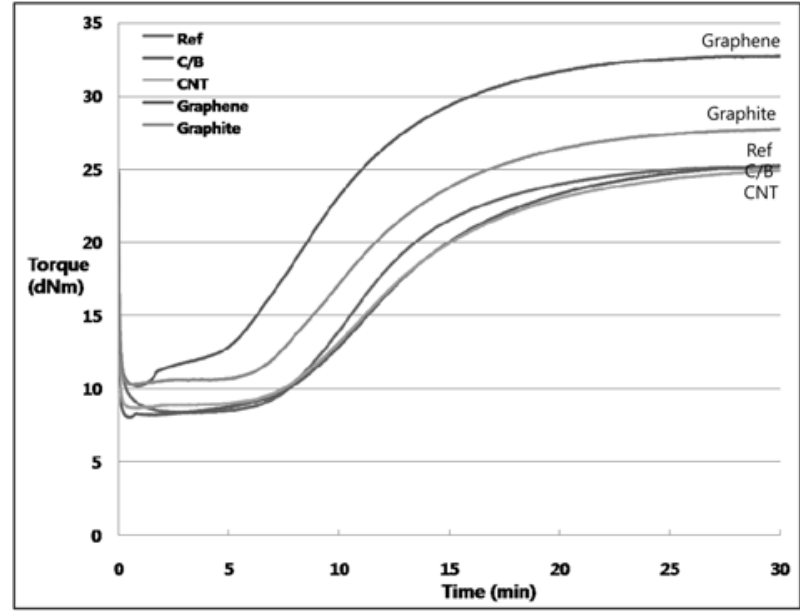

Fig. 3. Curing properties of carbon nanofillers/CBC.

specific surface by two dimensions.

That is to say, Graphene increases the bonding force with the rubber, and thermal conductivity through the result is also enhanced. However, the composites of the other carbon materials with different dimensions are similar with the cure properties because of the small specific surface.

$\mathrm{M}_{\mathrm{L}}$ is the lowest torque and $\mathrm{M}_{\mathrm{H}}$ is the highest torque at curing curves. $\mathrm{M}_{\mathrm{H}}-\mathrm{M}_{\mathrm{L}}$ represents the crosslink density of vulcanization. $\mathrm{M}_{\mathrm{H}}-\mathrm{M}_{\mathrm{L}}$ slightly increases after loading Graphene. This indicates that the addition of Graphene has

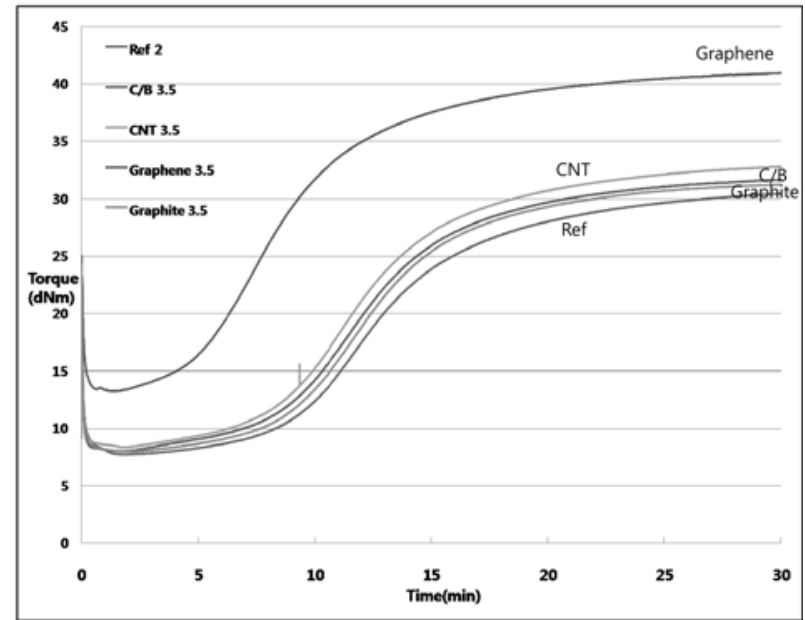

Fig. 4. Curing properties of carbon nanofillers/SBC.

a little effect on the crosslink density of rubber vulcanization.

The mechanical properties of carbon nanofillers/rubber composites are summarized in Table 4. From this table, shore A hardness of the composites of Graphene is highly increased, indicating that small additions of the filler largely influence the rubber matrix. In $\mathrm{CBC}$, the composite reinforced with Graphene showed about $115 \%$ increment over Ref 1 in modulus, while leaded to the decrement in both tensile strength and the elongation at break. And in

Table 3. Curing Properties of carbon nanofillers/SBR composites

\begin{tabular}{ccccccccccc}
\hline & $1($ Ref 1$)$ & 2 & 3 & 4 & 5 & 6 (Ref 2) & 7 & 8 & 9 & 10 \\
\hline T40 $(\min )$ & 10.6 & 11.3 & 11.3 & 8.2 & 10.1 & 11.8 & 11.2 & 11.0 & 7.6 & 11.5 \\
T90 $(\min )$ & 18.7 & 20.6 & 20.7 & 16.8 & 18.9 & 20.4 & 19.2 & 19.2 & 16.2 & 19.1 \\
$\begin{array}{c}\text { Min Torque } \\
\text { (ML, dNm) }\end{array}$ & 8.4 & 8.1 & 8.7 & 10.2 & 10.3 & 7.7 & 8.0 & 8.3 & 13.2 & 8.0 \\
$\begin{array}{c}\text { Max Torque } \\
\text { (MH, dNm) }\end{array}$ & 25.2 & 25.3 & 24.9 & 32.8 & 27.7 & 30.4 & 31.6 & 32.8 & 41.0 & 31.2 \\
$\Delta$ Torque & 16.8 & 17.2 & 16.2 & 22.6 & 17.4 & 22.7 & 23.6 & 24.5 & 27.8 & 23.2 \\
\hline
\end{tabular}


Table 4. Physical properties of carbon nanofillers/SBR composites.

\begin{tabular}{|c|c|c|c|c|c|c|c|c|c|c|}
\hline & $1(\operatorname{Ref} 1)$ & 2 & 3 & 4 & 5 & $6(\operatorname{Ref} 2)$ & 7 & 8 & 9 & 10 \\
\hline Hardness & 51 & 54 & 54 & 65 & 57 & 61 & 62 & 63 & 73 & 65 \\
\hline $\mathrm{M}-300 \%(\mathrm{MPa})$ & 4.51 & 4.9 & 4.51 & 8.33 & 5.1 & 5.98 & 6.47 & 6.96 & 10.49 & 6.67 \\
\hline $\begin{array}{l}\text { Tensile Strength } \\
\text { (MPa) }\end{array}$ & 18.52 & 17.54 & 17.35 & 17.44 & 16.76 & 20.48 & 20.48 & 18.82 & 17.64 & 20.48 \\
\hline Elongation (\%) & 746 & 714 & 761 & 623 & 724 & 720 & 720 & 640 & 510 & 690 \\
\hline $\begin{array}{c}\text { Electrical } \\
\text { Properties } \\
(\Omega)\end{array}$ & $1070 \mathrm{~K} \Omega$ & $425 \mathrm{~K} \Omega$ & $249 \mathrm{~K} \Omega$ & $31 \mathrm{~K} \Omega$ & $146 \mathrm{~K} \Omega$ & $768 \mathrm{G} \Omega$ & $662 \mathrm{G} \Omega$ & $507 \mathrm{G} \Omega$ & $160 \mathrm{G} \Omega$ & $460 \mathrm{G} \Omega$ \\
\hline $\begin{array}{c}\text { Thermal } \\
\text { Properties } \\
(\mathrm{W} / \mathrm{mK})\end{array}$ & 0.2756 & 0.2815 & 0.2931 & 0.2861 & 0.2897 & 0.2661 & 0.2707 & 0.2988 & 0.2814 & 0.2822 \\
\hline
\end{tabular}

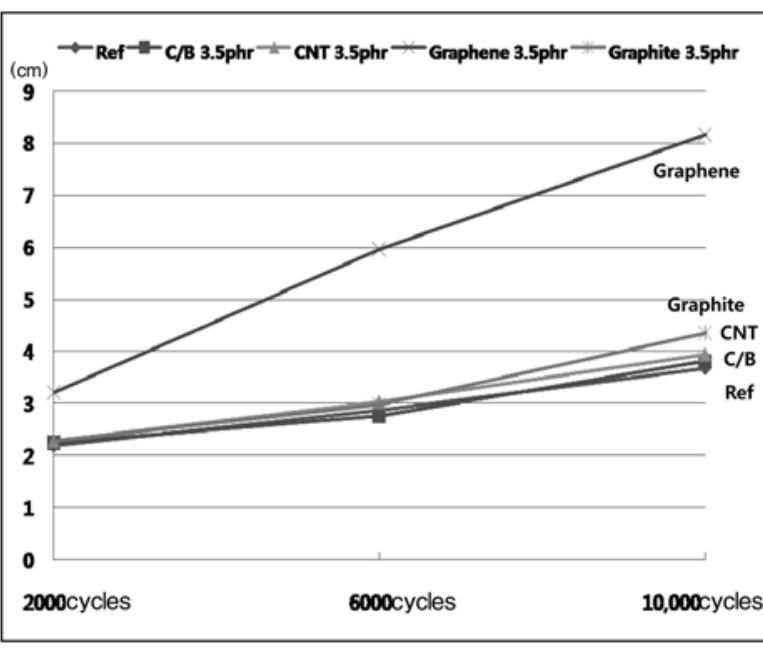

(a)

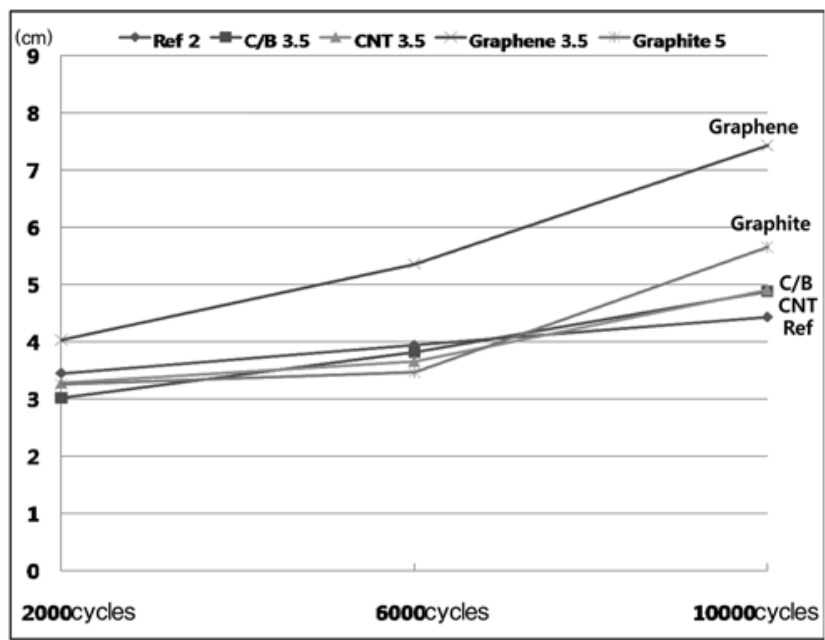

(b)

Fig. 5. Fatigue properties of carbon nanofillers/ SBR composites. a) Carbon-based composites and b) Silica-based composites.

$\mathrm{SBC}$, composite with Graphene also revealed about $75 \%$ increase in modulus over Ref 2, while the tensile strength and elongation at break are decreased $18 \%$ and $40 \%$ respectively. The composites using Graphene showed much higher reinforcement effects than conventional fillers, and the reason which is increased hardness and modulus of Graphene composites is due to the widest specific surface by the two-dimension. And, when rubber is compounded with carbon nanofillers, the mechanical properties are similar except for Graphene rubber composites. This reason is that the Graphene Composites increases the cross-linking density created by polymer-filler interactions as compared with other composites.

The fatigue properties of carbon nanofillers/rubber composites are shown in Fig. 5 and Table 5.

$$
\mathrm{dc} / \mathrm{dn}=\mathrm{AG}^{\alpha}
$$

Where, $\mathrm{c}$ is the crack length, $\mathrm{n}$ is the cycles, $\mathrm{G}$ is the tear energy.

Fatigue crack growths (dc/dn) of composites using carbon nanofilers are similar except graphene composites in both $\mathrm{CBC}$ and SBC. In other words, fatigue crack growth of composites using graphene is increased because the composites are more brittle than other rubber composites. This means that the tearing energy is decreased and fatigue life is increased from Eq. (1).

Thermal and electrical properties of carbon nanofillers/ rubber composites are shown Table 5. Generally, the specific heat and thermal conductivity of carbon systems are determined primarily by phonon. At low temperatures, the phonon contribution to these quantities dominates and is due primarily to acoustic phonons. And, the phonon specific heat of Graphene has a quadratic temperature contribution due to longitudinal acoustic and in-plane transverse 
Properties of Styrene-Butadiene Rubber Nanocomposites Reinforced with Carbon Black, Carbon Nanotube, Graphene, Graphite 109

Table 5. Fatigue properties of carbon nanofillers /SBR composites. (unit: $\mathrm{cm}$ )

\begin{tabular}{ccccccccccc}
\hline & 1 & 2 & 3 & 4 & 5 & 6 & 7 & 8 & 9 & 10 \\
\hline $\begin{array}{c}2000 \\
\text { cycles }\end{array}$ & 2.19 & 2.24 & 2.27 & 3.21 & 2.28 & 3.45 & 3.02 & 3.28 & 4.03 & 3.26 \\
$\begin{array}{c}6000 \\
\text { cycles }\end{array}$ & 2.86 & 2.76 & 3.03 & 5.97 & 2.98 & 3.94 & 3.82 & 3.66 & 5.36 & 3.47 \\
$\begin{array}{l}10,000 \\
\text { cycles }\end{array}$ & 3.67 & 3.81 & 3.95 & 8.17 & 4.35 & 4.43 & 4.88 & 4.91 & 7.43 & 5.66 \\
$\mathrm{dn} / \mathrm{dc}$ & 0.74 & 0.79 & 0.84 & 2.48 & 1.04 & 1.76 & 1.81 & 1.81 & 2.65 & 1.94 \\
\hline
\end{tabular}

acoustic phonons, and linear contribution due to the outof-plane transverse acoustic phonons. Also, the Graphite is dominated by the three acoustic phonons. In the case of the CNT, CNT yields linear wavevector dependence of all four acoustic branches: longitudinal, twist, and doublydegenerate transverse ones. ${ }^{26)}$ And also a large aspect ratio of the materials is advantageous for the thermal conductivity within the composite, as recognized by Yu et al.. ${ }^{27)}$

The electrical conducting mechanism of polymer composites is associated with two questions: 1) how to form the conducting paths and 2) how to conduct after the formation of the paths. Concerning the second question, several theories exist, such as contact conducting, the tunneling effect, dielectric breakdown, and field emission. It is generally believed that conductibility depends on their combined effect and could be summarized by the general statement that the microscopic migration of electrons might have several mechanisms. With regard to the first question, there are, for example, the percolation theory ${ }^{28)}$, the effective medium theory, ${ }^{29)}$ the microstructure theory, ${ }^{30)}$ and thermodynamic theory. ${ }^{31)}$ These theories are related to the dispersed morphology and internal microstructure of conducting fillers in polymer matrices.

In case of $\mathrm{CBC}$, in addition to improve the mechanical properties, Carbon Nanofillers impart conductivity to low resistivity elastomeric matrices. The electrical and thermal properties are improved by adding the carbon nanofillers due to facilitate the electrical and thermal transition through filler-filler and filler-matrix interactions. Especially, the CNT composite has the most predominant thermal property, and is increased nearly $7 \%$ compared with Ref 1 , because the CNT transfers the heat by four acoustic phonons, and the higher aspect ratio of MWNTs bundles increases the probability of particle-particle contacts. The composite using the graphite has the next best thermal properties by the three acoustic phonons, and then composite using the graphene has the thermal properties as follows by the two acoustic phonons according to the dimensions.
However, electrical property of Graphene composites is higher than any other composites. The reasons are that the Graphene particles with the large specific surfaces can abut or contact and then form a conducting network at lower Graphene contents. Also, while CNT and graphite have the metallic and semi-conductive properties, Graphene has metallic property of zero band gaps and is easy to make the formation of the conducting paths.

In case of SBC, Thermal properties are improved by adding the carbon nanofillers by the same reasons and the orders of the thermal conductivity are alike the orders of the $\mathrm{CBC}$. But, electrical properties of carbon nanofillers/ rubber composites are shown higher resistivity $\sim \mathrm{G} \Omega$, due to decrease the probability of particle-particle contacts by adding the small amounts. That is, there is a critical volume fraction known as the percolation threshold at which the conducting inclusions form an interconnecting filler network leading to a sharp drop in the electrical resistance. Below the critical volume fraction of carbon nanofillers, an interconnecting filler network is not formed, which results in a high increase of the electrical resistance of the nanocomposites.

\section{Conclusion}

Carbon nanofillers/SBR composites were prepared and evaluated their mechanical, fatigue, thermal and electrical properties according to the fillers. Rubber composites using graphene are improved the cure time and increased the crosslink density of rubber vulcanization.

And mechanical properties, the properties of the composites using other carbon nanofillers were similar except the graphene composites in both $\mathrm{CBC}$ and SBC.

That is, hardness of graphene rubber composites was sharply increased and modulus showed about $115 \%, 75 \%$ increment respectively over Ref 1 and Ref 2 , while the tensile strength and elongation at break were decreased in $\mathrm{CBC}$ and $\mathrm{SBC}$. 
In the fatigue properties, fatigue crack growths of composites using carbon nanofilers are similar except for the graphene-composites.

The composite using CNT has the most predominant thermal property by four acoustic phonons, and electrical property of composite using graphene is higher than any other composites due to metallic properties by zero band gaps in CBC. However, in case of SBC, the electrical properties of carbon nanofillers showed the $\sim \mathrm{G} \Omega$ resistivity because of decreasing the probability of particle-particle contacts by adding the small amounts. Thermal properties are impoved by adding the carbon nanofillers and the orders of the thermal conductivity are alike with $\mathrm{CBC}$.

The carbon nanofillers/SBR composites hold the promise of delivering exceptional mechanical properties and multifunctional characteristics.

The unique properties of the composites with carbon nanofillers are probably one of the most important processes in rubber industry and essentially in modern tire technology. Also, composites using carbon nanofillers in $\mathrm{CBC}$ will be excellent candidates for application in organic and hybrid electronics.

\section{References}

1. E. Guth, J Appl Phys 16, 20 (1944).

2. T. Kurian, P. P. De, D. Khastgir, D. K. Tripathy, S. K. De, D. G. Peiffer, Polymer, 36, 3875 (1995).

3. F. Yatsuyanagi, N. Suzuki, N. Ito, H. Kaidou, Polymer, 49, 9523 (2001).

4. D. W. Mccarthy, J. E. Mark, D. W. Schaffer, J Polymer Sci, Part B: Polymer Phys, 36, 1167 (1998).

5. Y. Ikeda, S. Poompradub, Y. Morita and S. Kohjiya. J SolGel Sci Technol, 45, 299 (2008).

6. L. Dewimille, B. Bresson, L. Bokobza, Polymer, 46, 4135 (2005).

7. S. Varghese, K. J. Karger, Polymer, 44, 4921 (2003).
8. M. Arroyo, M. A. Lopez-Manchado, B. Herrero, Polymer, 44, 2447 (2003).

9. P. Bala, B. K. Samantaray, S. K. Srivastava, G. B. Nando, J Appl Polymer Sci, 92, 3583 (2004).

10. E. Morales, J. R. White, J Mater Sci, 44, 4734, 2009.

11. G Sui, W. H. Zhong, X.P. Yang, Y. H. Yu, SH Zhao, PolymAdv. Technol, 19, 1543 (2008).

12. M. D. Frogley, D. Ravich, H. D. Wanger, Comp Sci Tech, 63, 1647 (2003).

13. M. Sumita, T. Tsukumo, K. Miyasaka, K. Ishikawa, J. Mater Sci 18, 1758 (1983).

14. S. Wang, R. Liang, B. Wang and C. Zhang Carbon, 47, 53 (2009).

15. L. Lu, Y. Zhai, Y. Zhang, C. Ong and S. Guo, Carbon. 255, 2162 (2008).

16. S. Wang, R. Liang, B. Wang, C. Zhang, Chem. Phys. Let. 457, 371 (2008).

17. A. Allaoui, S. Bai, H. M. Cheng and J. B. Bai, Comp. Sci. and Tech. 62, 1993 (2002).

18. S. Stabkovich, D. A. Dikin, R. D. Piner, K. A. Kohlhaas, A.Kleinhammes, Y. Jia, Y. Wu, S. T. Nguyen and R. S. Ruoff, Carbon 45, 1558 (2007).

19. A. Yasmin, I. M. Daniel, Polymer, 45, 8211-8219, (2004).

20. G. Chen, W. Weng, D. Wu, C. Wu, Polymer, 39, 2329, (2003).

21. J. W Shen, X. M Chen and W. Y Huang, J. appl. Polymer Sci. 88, 1864 (2003).

22. W. Zheng, S. C Wong and H. J Sue, Polymer 73, 6767 (2002).

23. H. Kim, C. W. Macosko, Polymer, 50, 3797 (2009).

24. R. Verdejo, S. A. Cristina, C. G. Javier, B. B. Fabienne, R. P. Miguel Angel, L. M. Miguel Angel, European Polymer Journal, 44, 2790 (2008).

25. J. Liang, Y. Wang, Y. Huang, Y. Ma, Z. Liu, J. Cai, C. Zhang, H. Gao, Y. Chen, Carbon, 47, 922 (2009).

26. V. N. Popov, J. Mater Sci, R43, 61 (2004).

27. A. Yu, P. Ramesh, M. E. Itkis, E. Bekyarova, R. C. Haddon, J Phys Chem C, 111, 7565 (2007).

28. C. Zhang, X. Yi, H. Yui, S. Asai, M. Sumita, J Appl Polym Sci, 69, 1813 (1998).

29. D. S. Mclachaln, Solid State Phys, 21, 1521 (1988).

30. M. Weber, M.R. Kamal, Polym Compos, 18, 711 (1997).

31. F. Lux, J Mater Sci, 28, 285 (1993). 